\title{
Evaluating the Effect of Showing the Dental Injector to Children on Their Dental Behavior in Relation to the Vital Signs And Maternal Anxiety
}

\author{
Muna Saleem Khalaf \\ Lecturer At The Department Of Pedodontics \& Preventive Dentistry, Baghdad Teaching Hospital, College Of \\ Dentistry, Baghdad University, Iraq.
}

\begin{abstract}
The main cause of this feeling is the dental injection. Many techniques for dental injection involved not showing the injector prior to the injection while others preferred showing the injector. It is believed that maternal anxiety affects the child's dental behavior. Many scales and signs can be used to determine the child's anxiety such as heart beat rate and respiratory rate. 31 children were involved in this study. The children were divided into two groups: group (a) children were shown the dental injector prior to local anesthesia administration, group (b) children were not shown the dental injector prior to local anesthesia administration. The behavior of the children was recorded during the dental injection using the Frankl scale. Maternal anxiety was evaluated using the Arabic version of the MDAS index. The vital signs recorded involved the heart beat rate and the respiratory rate. In group (a) the behavior of the children during dental injection was mostly definitely positive (code 4). While in group (b) it was mostly definitely negative (code 1). Most of the mothers had a moderate level of anxiety (35\%) and their children behaved in a favorable way. The heart rate of the children of both groups was higher in group (a) than in group (b) at all times although it was not statistically significant. The difference in respiratory rates at all times between both groups was also not significant. Showing the dental injector to the child prior to injection and following the "tell-show-do" technique affects the behavior of the child in a favorable way. Children behaved favorably in a positive way in accordance to their mother's level of anxiety. The presence of the mother in the dental operatory with her child may have an effect on the behavior.
\end{abstract}

Keywords: showing dental injectors, maternal anxiety, vital signs, child behavior.

\section{Introduction}

Local anesthesia is one of the most delicate and difficult procedures in pediatric dental treatment. Injection of the anesthetic solution produces the greatest negative response in children ${ }^{[1]}$. Pain and anxiety can reduce the efficacy of anesthesia in pediatric patients ${ }^{[2]}$. Anxiety is the most disturbing experience for children, sometimes requiring techniques beyond local anesthesia to control it.

The fear of the needle and the pricking, which is associated with the word "injection", makes children anxious. Many techniques have been followed to reduce dental fear and anxiety for the child patient. One of these techniques was showing the needle in the final steps of a desensitization process ${ }^{[3]}$. Another was showing the needle to the child before administration of anaesthesia, because if not shown, the child may imagine a needle that is much larger and procedure more painful than they actually are ${ }^{[4]}$. Addelston introduced the "tellshow-do" technique ${ }^{[5]}$. This technique aimed to guide the behavior and reduce the normal fear of children, during different stages of their psychological development. Mink and Spedding described the concealed technique. In this technique the child was not shown the syringe throughout the dental visit ${ }^{[6]}$.

Fearful and anxious children obtain poorer dental care. Their negative reaction and refusal to be treated make them avoid dental visits until pain in a tooth brings them to the clinic. This emergency and anxiety make the parents prefer extraction rather than restoration of decayed teeth. The dentist himself might avoid performing treatment for fearful children because of their uncooperative behavior ${ }^{[7]}$.

There are many factors that have been proposed to stimulate dental anxiety in children. One of these factors is the influence of parental anxiety on dental treatment of child. Dental anxiety in children might be due to maternal anxiety, family influences, personality and psychological development of the children, and previous painful medical and dental experience ${ }^{[8,9]}$. It has been believed that anxiety in a child "develops with the existence of anxious people around them". Although it is believed that parental attitude influences the child's behavior in a dental visit and a negative reaction is noticed in children of highly anxious parents, some researchers considered maternal anxiety as the primary factor influencing child behavior ${ }^{[10]}$.

An anxious patient may develop symptoms of restlessness, tension, tachycardia and dyspnea ${ }^{[11]}$. The psychophysiological responses produced by anxiety are associated with an increase in the activity of the sympathetic branch of the autonomic nervous system. The cardiovascular system may also undergo changes 
involving increased blood pressure and pulse rate. Changes in the respiratory system may involve sighs and feeling breathless ${ }^{[12]}$.

The aim of this study is to evaluate the effect of showing and not showing the dental injector to the child, in his first dental visit prior to local anesthesia administration, on his behavior, heart beat rate and respiratory rate. It is also tended to study if maternal anxiety is related to the child's dental fear.

\section{Materials And Method}

The participants were selected from the children attending the Department of Pedodontic and Preventive Dentistry at the College of Dentistry, University of Baghdad. The selection of children was aimed at forming a study group that consisted of children that attended the dental clinic for the first time in their lives and did not have a previous experience of local anesthesia applied with a dental injector. 31 children of ages that ranged between 6-9 years were included.

After obtaining parental consent and using the "tell-show-do" technique, the aim of the study and procedure was described to the mother. The children were divided into two groups: group (a): in this group the injector was shown in the first session before anaesthetic administration. After showing the syringe, the child was asked to help by holding the syringe, and then the dentist assembled the syringe, anaesthetic cartridge and needle while the child watched. The second group: group (b): in this group the child didn't see the dental syringe or the procedure of preparing the anesthetic solution and needle. The child was told that his tooth would fall asleep, but he would stay awake and that it might feel like a slight prick. Anesthesia administration was performed by the dental student as the researcher observed the behavior of the child. The behavior was observed and recorded during the administration of anesthesia according to Frankl scale (Table 1) ${ }^{[8]}$.

The vital signs of the child that were recorded included heart beat per minute and respiratory rate per minute. They were recorded before, during and after the administration of anesthesia. Heart rate was recorded using a digital device applied to the wrist of the child (Tensoval ${ }^{\circledR}$ Heartmann, Heidenheim, Germany). Respiratory rate was recorded by the author's hand being placed on the abdomen of the child and counting the number if inhales the child takes in per 30 seconds multiplied by two (one minute of time) ${ }^{[13]}$.

Maternal anxiety was evaluated by the use of the Arabic version of the Modified Dental Anxiety Scale (MDAS) index (Fig 1) ${ }^{[14]}$. Scoring was assigned to five categories of anxiety and with a high score denoting a highly anxious response. Scores equal to or exceeding 19 on MDAS have been related to a very high level of dental fear (possibly phobic) in adults ${ }^{[9,15]}$.

The questionnaires were given to the mother, while the child was receiving treatment, to fill and return (during the same visit).

Fig 1: The Arabic version of the Modified Dental Anxiety Scale (MDAS) index.

\begin{tabular}{|c|c|c|c|}
\hline \multicolumn{4}{|c|}{ 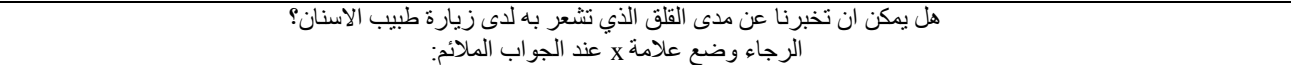 } \\
\hline \multicolumn{4}{|c|}{ ا ـ لو ذهبت لزيارة طبيب الأسنان للعلاج غدا، كبف سيكون شعورك؟ } \\
\hline ه قلق إلى أبعد الحدود & مقلق جدا & لـقلق & ـقَّق قليلا \\
\hline \multicolumn{4}{|c|}{ r. إذا كنت جالسا في غرفة الإنتظار (في إنتظار العلاج لأسنانك)، كيف سيكون شعورك؟ } \\
\hline ـ ق قلق إلى أبعد الحدود & مقلق جدا & مـقلق & مقتلق قليلا \\
\hline \multicolumn{4}{|c|}{ r. إذا كنت على وشك أن تتعرض لعلاج ضرسك بالحفر، كيف سيكون شعورك؟ } \\
\hline ـ ق قلق إلى أبعد الحدود & مقلق جدا & مـقلق & مـقّق قليلا \\
\hline \multicolumn{4}{|c|}{ ـ ـ إذا كنت على وشك أن تتعرض للتظليف وتلميع الأسنان، كيف سيكون شعورك؟ } \\
\hline ـ قلق إلى أبعد الحدود & مقلق جذا & مقلق & مقلق قلبلا \\
\hline & كيف سيكون & 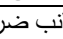 & 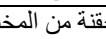 \\
\hline 口 قلق إلى أبعد الحدود & مقلق جدا & مقلق & ــقلق قليلا \\
\hline
\end{tabular}

Information gathered on the cooperation of each child was expressed by rating with code from 1 to 4 on Frankl scale. Maternal anxiety was expressed by score for each item and the sum of the scores for each mother was calculated and rated according to the table for anxiety rating (table 1). It was expressed in numbers and percentage values. The vital signs analysis was done by the use of the SPSS version 20. It involved the mean values and independent sample t-test for differences between the groups.

Table 1: Frankl scale adapted for local anesthesia

\begin{tabular}{|l|c|l|}
\hline Behavior & Rating & Description \\
\hline Definitely negative & 1 & $\begin{array}{l}\text { Refusal of anesthesia administration, crying forcefully, fearful, or any other evidence of extreme } \\
\text { negativism. }\end{array}$ \\
\hline Negative & 2 & $\begin{array}{l}\text { Reluctant to accept anesthesia administration, uncooperative, some evidence of negative attitude but } \\
\text { not pronounced, i.e. sullen, withdrawn. }\end{array}$ \\
\hline Positive & 3 & $\begin{array}{l}\text { Acceptance of anesthesia administration, at times cautious, willingness to comply with the dentist, } \\
\text { at times with reservation but patient follows the dentist's directions cooperatively. }\end{array}$ \\
\hline Definitely positive & 4 & $\begin{array}{l}\text { Good rapport with the dentist, interested with the dental procedures, laughing and enjoying the } \\
\text { situation. }\end{array}$ \\
\hline
\end{tabular}


Table 2: Anxiety rating for the mothers ${ }^{(15)}$

\begin{tabular}{|l|l|}
\hline Anxiety level & Score \\
\hline No or low anxiety & $<9$ \\
\hline Moderate anxiety & $9-12$ \\
\hline High anxiety & $13-14$ \\
\hline Severe anxiety/phobia & $15-20$ \\
\hline
\end{tabular}

\section{Results}

The children involved in this study were 32 children. All of them were included except for one child. This child was excluded just before the administration of anesthesia on the demand of the mother who showed severe anxiety and refused to continue the treatment of her child based on her negative experience. Table 3 shows the distribution of the children of both groups according to their level of cooperation on Frankl scale. Group (a) involved 15 children of whom their cooperation was mostly at the level code 4 . While for group (b) 16 children were involved and their cooperation was mostly at the level code 1 .

Table 3: Cooperation of children in group a and b (dental syringe shown/not shown prior to anesthesia administration)

\begin{tabular}{|c|c|c|c|c|c|}
\hline & \multicolumn{4}{|c|}{ Cooperation of the children } & \multirow{2}{*}{$\begin{array}{l}\text { Total no. of } \\
\text { children } \\
(31)\end{array}$} \\
\hline & Code 1 & Code 2 & Code 3 & Code 4 & \\
\hline Group a & 1 & - & 5 & 9 & 15 \\
\hline Group b & 8 & 4 & 2 & 2 & 16 \\
\hline
\end{tabular}

Table 4 describes the effect of maternal anxiety on the child's behavior during anesthesia administration. $35.5 \%$ of mothers had a moderate level of anxiety and most of their children expressed a positive cooperation behavior (code $3 ; 36.3 \%$ ). Mothers with low anxiety towards dental treatment had children that behaved definitely positive (55.6\%) and definitely negative $(33.3 \%)$. Children of mothers that had severe anxiety towards dental treatmentshowed a behavior that was positive and definitely positive more than a negative behavior (code 3: $25 \%$ and code 4: 37.5\%). Few mothers had high anxiety $(n=3,9.6 \%)$ and in accordance to this their children showed negative behavior during anesthesia administration ( 2 of 3 children).

Table 4: Effect of maternal anxiety on child behavior

\begin{tabular}{|l|l|l|l|l|}
\hline Maternal anxiety & Child behavior & \multicolumn{2}{l|}{} \\
\cline { 2 - 5 } N $(\%)$ & Code 1 & Code 2 & Code 3 & Code 4 \\
\hline No or low anxiety & 3 & - & 1 & 5 \\
N=9 $(29 \%)$ & $(33.3 \%)$ & & $(11.1 \%)$ & $(55.6 \%)$ \\
\hline Moderate anxiety & 2 & 3 & 4 & 2 \\
N=11 (35.5\%) & $(18.2 \%)$ & $(27.3 \%)$ & $(36.3 \%)$ & $(18.2 \%)$ \\
\hline High anxiety & 1 & 1 & - & 1 \\
N=3 $(9.6 \%)$ & $(33.3 \%)$ & $(33.3 \%)$ & & $(33.3 \%)$ \\
\hline Severe anxiety/phobia & 3 & - & 2 & 3 \\
N=8 $(25.8 \%)$ & $(37.5 \%)$ & & $(25 \%)$ & $(37.5 \%)$ \\
\hline Total =31 & 9 & 4 & 7 & 11 \\
\hline
\end{tabular}

Table 5 depicts the heart rate and respiratory rate for children in both groups before, during and after the injection of local anesthesia. The heart beat rate was higher in children of group $b$ at all times although statistically the difference was not significant. The respiratory rate of the children of both groups ranged between 24-29 breaths per minute. The difference between groups was also not significant.

Table 5: Heart beat rates and respiratory rates for children before, during and after injection for local anesthesia

\begin{tabular}{|c|c|c|c|c|c|c|c|}
\hline & \multicolumn{3}{|c|}{ Heart beat rate* } & \multicolumn{3}{|c|}{ Respiratory rate** } \\
\hline & & Mean & t-test & $\mathrm{p}$-value & mean & t-test & $p$-value \\
\hline \multirow{2}{*}{$\begin{array}{l}\text { Before dental } \\
\text { injection }\end{array}$} & Group a & 96.67 & \multirow{2}{*}{0.830} & \multirow{2}{*}{$\begin{array}{l}0.413 \\
\text { NS }\end{array}$} & 28.6 & \multirow{2}{*}{2.21} & \multirow{2}{*}{$\begin{array}{l}0.035 \\
\text { NS }\end{array}$} \\
\hline & Group b & 101.4 & & & 24.8 & & \\
\hline \multirow{2}{*}{$\begin{array}{l}\text { During } \\
\text { dental } \\
\text { injection }\end{array}$} & Group a & 108.6 & \multirow{2}{*}{1.079} & \multirow{2}{*}{$\begin{array}{l}0.29 \\
\text { NS }\end{array}$} & 29.3 & \multirow{2}{*}{0.342} & \multirow{2}{*}{$\begin{array}{l}0.735 \\
\text { NS }\end{array}$} \\
\hline & Group b & 114.6 & & & 28.6 & & \\
\hline \multirow{2}{*}{$\begin{array}{l}\text { After dental } \\
\text { injection }\end{array}$} & Group a & 95.7 & \multirow{2}{*}{0.834} & \multirow{2}{*}{$\begin{array}{l}0.41 \\
\text { NS }\end{array}$} & 25.9 & \multirow{2}{*}{0.304} & \multirow{2}{*}{$\begin{array}{l}0.763 \\
\text { NS }\end{array}$} \\
\hline & Group b & 99.1 & & & 25.4 & & \\
\hline
\end{tabular}

$\mathrm{Df}=29$. NS: not significant at level $\mathrm{p}<0.05$. *Normal heart rate for $6-12$ years old children $=80-120$ beats per minute. ${ }^{*}$ Normal respiratory rate for $6-12$ years old children $=25-40$ breaths per minute ${ }^{(13)}$ 


\section{Discussion}

Anxious children tend to have oral health comparatively poor with regard to less anxious and more cooperative peers. In this study most of the children of group (a); that were shown the dental injector prior to anesthesia administration were positive and definitely positive. In this group only one child was very negative in his cooperation. While in group (b); in which the dental injector was hidden from the child's view the children mostly exhibited a negative and definitely negative cooperation. Showing the injector and explaining the procedure of injection and what is expected to be felt lessens the fear of the child ${ }^{[4]}$. In teaching curriculums it is advised to hide the needle and ask the child to close his eyes during the administration of local anesthesia and in the same curriculums it is also advised to follow the "tell-show-do" technique to relax the child and knowledge him of what is to be expected. The results of this study and a study previously conducted on the type of injector used both suggest showing the injector and explaining the procedure. Of course it is also suggested to use imaginary scenes or distraction technique to take their minds away from the task at hand ${ }^{[16]}$. Others studies also do not support the practice of hiding the needle. Initially hiding the needle followed by Tell-Show-Do technique gave more positive behavior in children when adapted ${ }^{[17]}$.

Most of the mothers accompanying their children for dental treatment showed moderate anxiety (35.5\%). Their children showed behavior ranging from definitely negative to definitely positive (code 1-4) being more positive than negative. The mothers of low anxiety had children that behaved positively more than negatively. A negative behavior was seen in children of highly anxious mothers. This finding came in agreement with that of Kanwal ${ }^{[18]}$ whose results showed a positive correlation between the child's behavior and his parental anxiety. Children usually depend on their parents who in turn have a strong and dominant influence on their children. Severely anxious mothers had children that behaved positively during local anesthesia. The anxiety of their mothers didn't influence their behavior. This result was confusing. It may be explained that the etiology of child dental fear is considered multifactorial. In general the child's ways of reacting to adverse medical situations have been related to the medical setting and parental presence ${ }^{[19]}$. During the administration of anesthesia the mother was asked to stay with the child in the dental operatory. This may have had an effect on the child's behavior since it has been concluded that children are likely to experience less distress during a dental injection if a parent is present ${ }^{[4]}$.

The physiological index recorded in our study included the heart beat rate and respiratory rate. It was observed that the heart beat rate was higher in children who did not see the dental injector before or during the injection. Although statistically the difference was not significant, it can indicate that those children were more anxious than the ones who saw the injector. Anxiety in children may be manifested in many ways. Some children respond in a disruptive or an interruptive behavior. Others may respond by sweating and an increase in heart beat rate. Some children don't show any external sign of anxiety ${ }^{[20]}$. The difference between the respiratory rates of the children at the different times of dental injection also was not significant.

\section{Conclusion}

As conclusion showing the dental injector to the child prior to injection and following the "tell-showdo" technique affects the behavior of the child in a favorable way. Children behaved favorably in a positive way in accordance to their mother's level of anxiety. The presence of the mother in the dental operatory with her child may have an effect on the behavior.

\section{References}

[1]. McDonald RE, Avery D. Local anesthesia for the child and adolescent. In: Dentistry for the Child and Adolescent. 7th Ed. St. Louis: CV Mosby Co. 2000; 283-284.

[2]. McGrath PJ: Psychologic Perspectives on Pediatric Pain. J Pediatr. 122(5 Pt 2), 1993, S2-S8.

[3]. Glassman P, Peltier B. Guidelines for the administration of local anesthesia in fearful dental patients. J Calif Dent Assoc. 23, 1995, 23-26.Duff AJA. Incorporating psychological approaches into routine paediatric venipuncture. Arch Dis Child. 88, 2003 , $931-937$.

[4]. Addelston HK. Child patient training. Fortn Rev Chic Dent Soc, 38:(7-9), 1959, 27-29.

[5]. Spedding, RH, Mink JR. An approach to the injection procedure for the child patient. J N J State Dent Soc, 35,1964 161-168.

[6]. Zwain AMH, Salih BA. Assessment of dental anxiety by physiological measurement (salivary cortisol) and psychological measurement (dental anxiety scale) in children. Journal of Babylon University. Pure and Applied Sciences. 22 (9), 2014, 25682578 .

[7]. Klingberg G, Berggren U, Noren JG. Dental fear in an urban Swedish child population: prevalence and concomitant factors. Community Dent Health. 11, 1994, 208-214.

[8]. Freeman RE. Dental anxiety: multifactorial aetiology. Br Dent J. 159, 1985, 406-408.

[9]. Dikshit P, Limbu S, Bhattarai K. Evaluation of dental anxiety in parents accompanying their children for dental treatment. Orthodontic Journal of Nepal. 3(1), 2013, 47-52.

[10]. Ahmead M, Rahhal A. Assessment of the prevalence of dental anxiety among palestinian clients attending dental clinics in bethlehem city: cross sectional study. Psychology and Behavioral Sciences. 3(6), 2014, 197-202.

[11]. Guinot Jimeno F, Yuste Bielsa S, Cuadros Fernández C, Lorente Rodríguez A I, Mercadé Bellido M. Objective and subjective measures for assessing anxiety in paediatric dental patients. European Journal of Paediatric Dentistry. 12(4), 2011, $239-244$.

[12]. Sudbury, Mass, Jones, Bartlett. Pediatric Education for Prehospital Professionals ( $2^{\text {nd }}$ edition). American Academy of Pediatrics, 2000, pp 43-45. 
[13]. Arabic version of the MDAS index. School of Medicine. Medical and Biological Sciences Building, University of St Andrews http://www.st-andrews.ac.uk/dentalanxiety/scaletranslations/. 2015.

[14]. Ilgüy D, Ilgüy M, Dinçer S, Bayirli G. Reliability and validity of the Modified Dental Anxiety Scale in Turkish patients. J Int Med Res. 33(2), 2005, 252-9.

[15]. Khalaf MS. Children preference of dental injectors and its influence on child cooperation. J Bagh College Dentistry. 23(1), 2011, 131-133.

[16]. Maragakis GM, Musselman RJ, Ho CC. Reaction of 5 and 6 year olds to dental injection after viewing the needle: pilot study. J Clin Pediatr Dent. 31(1), 2006, 28-31.

[17]. Kanwal F, Jamil Y, Khan H. Effect of parental anxiety on child behaviour in the dental surgery. JKCD. 2(2), 2012, 74-77.

[18]. Bush JP, Melamed BG, Sheras PL, Greenbaum PE. Mother-child patterns of coping with anticipatory medical stress. Health Psychol. 5, 1986, 137-57.

[19]. Ayer WA Jr, Domoto PK, Gale N, Joy ED Jr, Melamed BG. Overcoming dental fear: strategies for its prevention and management. J Am Dent Assoc. 107(1), 1983, 18-27. 